\title{
Hubungan Antara Persepsi Tentang Lingkungan Pembelajaran Klinik dan Tingkat Kecemasan Mahasiswa Program Profesi Dokter
}

\author{
The Relationship Between Perception of the Clinical Learning Environment and the Anxiety Level \\ of Professional Doctor Program Students
}

\author{
Harleyna Rokhison ${ }^{1}$, Anis Kusumawati ${ }^{1}$, Yuhantoro Budi Handoyo Sakti ${ }^{1}$, Agus Zuliyanto ${ }^{1}$ \\ ${ }^{1}$ Fakultas Kedokteran, Universitas Muhammadiyah Purwokerto, Indonesia \\ *Penulis Korespondensi. Email: harleynarokhison@gmail
}

Telp: +62-857 29774202

\begin{abstract}
Abstrak
Latar Belakang: Pendidikan klinik memiliki suasana lingkungan belajar yang sangat berbeda dengan pendidikan di tahap akademik. Persepsi lingkungan belajar memburuk disaat mahasiswa memulai pengalaman klinik dan lingkungan belajar klinik merupakan salah satu sumber kecemasan yang cukup besar. Dalam model Biggs kecemasan dianggap sebagai variabel penghalang akibat interaksi antara mahasiswa dan lingkungannya. Tinggi rendahnya kecemasan akan berpengaruh terhadap tingkat kompetensi mahasiswa. Penelitian bertujuan mengetahui hubungan antara persepsi tentang lingkungan pembelajaran klinik dan tingkat kecemasan mahasiswa program profesi dokter.

Metode: Penelitian analitik observasional dengan pendekatan cross-sectional, melibatkan 41 responden mahasiswa program profesi dokter angkatan 2013 Fakultas Kedokteran Universitas Muhammadiyah Purwokerto di RSUD dr. Soeselo Slawi dengan total sampling, analisis data menggunakan uji korelasi Pearson.

Hasil: Hasil penelitian menunjukan persepsi lingkungan belajar klinik kurang baik sebanyak 24,4\%, cukup baik $68,3 \%$, dan baik 7,3\%. Tingkat kecemasan mahasiswa didapatkan tidak cemas-cemas ringan 41,5\%, cemas ringan-sedang $56,1 \%$, dan cemas sedang-berat $2,4 \%$. Analisis pearson menunjukan terdapat hubungan yang signifikan antara persepsi lingkungan pembelajaran klinik dan tingkat kecemasan mahasiswa program profesi dokter dengan $\mathrm{P}$ value $0,006(\mathrm{P}=$ $<0,05)$.
\end{abstract}

Kesimpulan: Terdapat hubungan yang signifikan antara persepsi lingkungan pembelajaran klinik dan tingkat kecemasan mahasiswa program profesi dokter.

Kata Kunci: Lingkungan Belajar Klinik, Kecemasan, Mahasiswa, Program Profesi Dokter

\begin{abstract}
Background: Education clinic has the atmosphere of a very different learning environment with education in the academic stage. Perception learning environment deteriorated when students start clinical experience and clinical learning environment is a source of anxiety is quite large. In a model of anxiety Biggs is considered as a variable barrier due to the interaction between the students and the environment. Level of anxiety will affect the level of student competency. Study aims to determine whether there is a relationship between the perception of clinical learning environment and anxiety levels of students of the medical profession.

Method: An observational analytic study with cross-sectional approach, involving 41 respondents students of the medical profession in 2013 FK UMP forces in dr. Soeselo Slawi with a total sampling, data analysis using Pearson correlation test.

Result: The results showed perceptions of clinical learning environment is not good as much as $24.4 \%$, $68.3 \%$ is good enough, and a good $7.3 \%$. Anxiety level of students was found not to be mildly anxiety $41.5 \%$, mild-moderate anxiety $56.1 \%$, and moderate to severe anxiety $2.4 \%$. Pearson analysis showed a significant relationship between the perception of clinical learning environment and anxiety levels of students of the medical profession with a $P$ value of $0.006(P=<0.05)$.
\end{abstract}

Conclusion: There is a significant relationship between the perception of clinical learning environment and anxiety levels of students of the medical profession.

Keywords: clinical learning environment, anxiety, student, medical profession program. 


\section{PENDAHULUAN}

Pendidikan klinik memiliki suasana lingkungan belajar yang sangat berbeda dengan pendidikan di tahap akademik. Perubahan pendidikan akademik menjadi pendidikan klinik berkaitan dengan lingkungan belajar yang baru. Lingkungan belajar pada mahasiswa meliputi lingkungan fisik, isi pembelajaran, dan budaya pada pembelajaran mahasiswa. ${ }^{1}$ Biggs (1987) menawarkan kerangka untuk memahami proses belajar mahasiswa dengan model 3P, yang meliputi presage, proses dan product. Model ini dikemukakan berdasarkan pemahaman bahwa kebiasaan terbentuk dari adanya interaksi antar manusia dan lingkungan. ${ }^{2}$

Berdasarkan penelitian pada mahasiswa kedokteran di Kanada tahun 2010 dan 2011 didapatkan bahwa persepsi lingkungan yang memburuk terjadi pada tahun ke-3 sekolah kedokteran, disaat mereka memulai pengalaman klinik. $^{3}$ Penyebab masalah dalam menjalani pembelajaran klinik diantaranya karena mahasiswa baru pertama kalinya menghadapi pembelajaran klinik, pemahaman yang terbatas terhadap tugas profesi, lingkungan baru dan pengalaman pertama berinteraksi dengan pasien ${ }^{4}$ Transisi dari pembelajaran kelas ke pembelajaran klinik dapat menyebabkan stres yang tinggi. ${ }^{5}$

Kecemasan adalah fenomena umum dalam kehidupan sehari-hari. ${ }^{6}$ Gangguan kecemasan biasanya disebabkan oleh kombinasi biologis, psikologis dan faktorfaktor sosial. Suatu gangguan kecemasan juga dapat muncul karena pola fikir yang negatif terhadap sesuatu yang dilakukan. ${ }^{7}$ Tiga sumber utama dari kecemasan pada mahasiswa tahap klinik yaitu: takut, kesulitan transisi, dan relasi yang tidak mendukung. ${ }^{8}$ Kecemasan merupakan penghambat mayor pembelajaran di klinik, hal ini menyebabkan mahasiswa tidak mampu bekerja dengan baik. $^{9}$ Berdasarkan wawancara dengan mahasiswa, kondisi cemas yang mereka alami merupakan salah satu hambatan proses pembelajaran. ${ }^{10}$ Pengalaman di bidang klinis juga merupakan salah satu sumber kecemasan mahasiswa. ${ }^{11}$ Hal ini di perkuat oleh penelitian yang dilakukan Emilia (2008) menyatakan konteks pembelajaran praktik lebih tidak terstruktur dibanding perkuliahan sehingga mahasiswa lebih banyak menghadapi kecemasan, stres dan tekanan. ${ }^{5}$

Penelitian lain menyebutkan bahwa tingkat kecemasan mahasiswa kebidanan yang mengikuti pendidikan klinik didapatkan hasil, tidak cemas sampai ringan sebanyak $19,05 \%$, ringan sampai sedang $66,67 \%$, dan sedang sampai berat $14,28 \% .^{12}$ Dalam model Biggs kecemasan dianggap sebagai variabel penghalang akibat interaksi antara mahasiswa dan lingkungannya. Kecemasan bertindak sebagai penyaring yang dapat mendorong atau sebaliknya menghambat belajar mahasiswa. Keberhasilan mahasiswa dalam memenuhi beban pembelajaran akan mempengaruhi pendekatan dan keberhasilan belajar mahasiswa yang ditunjukkan dengan prestasi nyata dan persepsi terhadap pencapaiannya. ${ }^{5}$ Penelitian mengenai hubungan lingkungan belajar klinik dengan tingkat kecemasan mahasiswa pada mahasiswa program Ners pernah dilakukan menggunakan kuesioner Student Evaluation of Clinical Education Environment (SECEE) dan Depression Anxiety Stress Scale (DASS). ${ }^{13}$ Penelitian pada mahasiswa pendidikan profesi dokter di Indonesia jarang dilakukan, sehingga perlu dilakukan penelitian mengenai hubungan antara persepsi tentang lingkungan pembelajaran klinik dan tingkat kecemasan mahasiswa program profesi dokter.

\section{METODE}

Penelitian ini adalah observasional analitik dengan rancangan penelitian cross sectional. Populasi penelitian ini adalah seluruh Mahasiswa Program Profesi Dokter Fakultas Kedokteran Universitas Muhammdiyah Purwokerto (FK UMP) di RSUD dr. Soeselo Slawi. Teknik sampling yang digunakan yaitu total sampling. Besar subjek pada penelitian ini sebanyak 41 mahasiswa. Variabel lingkungan belajar 
klinik diukur menggunakan kuesioner lingkungan pembelajaran, dan tingkat kecemasan diukur menggunakan kuesioner tingkat kecemasan. Analisis menggunakan uji korelasi Pearson. Penelitian ini telah mendapat izin etik dari Komisi Etik Penelitian dan Kesehatan (KEPK) FK UMP dengan nomor referensi KEPK/FK/VII/102/2018.
HASIL

Hasil penelitian berdasarkan Tabel 1 di dapatkan persepsi lingkungan belajar klinik yang kurang baik sebanyak 10 responden $(24,4 \%), 28$ responden $(68,3 \%)$ menilai lingkungan belajar klinik cukup baik, dan 3 responden $(7,3 \%)$ menilai lingkungan belajar klinik sudah baik.

Tabel 1. Persepsi Lingkungan Belajar Klinik

\begin{tabular}{ccccccccc}
\hline \multirow{2}{*}{ No } & \multirow{2}{*}{ Stase } & $\mathrm{N}$ & \multicolumn{6}{c}{ Persepsi Lingkungan Belajar } \\
\cline { 3 - 8 } & & & $\sum$ & $\%$ & $\sum$ & $\%$ & $\sum$ & $\%$ \\
\hline \multirow{2}{*}{1} & Bedah & 10 & 3 & 7,32 & 7 & 17,07 & 0 & 0 \\
2 & Obsgyn & 7 & 3 & 7,32 & 4 & 9,76 & 0 & 0 \\
3 & Saraf & 5 & 0 & 0 & 5 & 12,19 & 0 & 0 \\
4 & Mata & 4 & 0 & 0 & 2 & 4,88 & 2 & 4,86 \\
5 & THT & 5 & 2 & 4,88 & 3 & 7,32 & 0 & 0 \\
6 & Psikiatri & 5 & 1 & 2,44 & 3 & 7,32 & 1 & 2,44 \\
7 & Anastesi & 5 & 1 & 2,44 & 4 & 9,76 & 0 & 0 \\
\hline & Total & 41 & 10 & 24,4 & 28 & 68,3 & 3 & 7,3 \\
\hline
\end{tabular}

Tabel 2. Tingkat Kecemasan

\begin{tabular}{|c|c|c|c|c|c|c|c|c|}
\hline \multirow{3}{*}{ No } & \multirow{3}{*}{ Stase } & \multirow{3}{*}{$\mathrm{N}$} & \multicolumn{6}{|c|}{ Tingkat Kecemasan } \\
\hline & & & \multicolumn{2}{|c|}{$\begin{array}{l}\text { Tidak cemas - } \\
\text { cemas ringan }\end{array}$} & \multicolumn{2}{|c|}{$\begin{array}{c}\text { Cemas ringan - } \\
\text { sedang }\end{array}$} & \multicolumn{2}{|c|}{$\begin{array}{c}\text { Cemas sedang - } \\
\text { berat }\end{array}$} \\
\hline & & & $\sum$ & $\%$ & $\sum$ & $\%$ & $\sum$ & $\%$ \\
\hline 1 & Bedah & 10 & $\overline{5}$ & 12,20 & $\overline{5}$ & 12,19 & 0 & 0 \\
\hline 2 & Obsgyn & 7 & 0 & 0 & 7 & 17,07 & 0 & 0 \\
\hline 3 & Saraf & 5 & 5 & 12,20 & 0 & 0 & 0 & 0 \\
\hline 4 & Mata & 4 & 4 & 9,76 & 0 & 0 & 0 & 0 \\
\hline 5 & THT & 5 & 1 & 2,44 & 4 & 9,75 & 0 & 0 \\
\hline 6 & Psikiatri & 5 & 0 & 0 & 5 & 12,19 & 0 & 0 \\
\hline \multirow[t]{2}{*}{7} & Anastesi & 5 & 2 & 4,88 & 2 & 4,87 & 1 & 2,4 \\
\hline & Total & 41 & 17 & 41,5 & 23 & 56,1 & 1 & 2,4 \\
\hline
\end{tabular}

Hasil penelitian berdasarkan Tabel 2 di dapatkan tingkat kecemasan tidak cemascemas ringan sebanyak 17 responden $(41,5 \%)$, cemas ringan-sedang sebanyak 23 responden $(56,1 \%)$, dan cemas sedang-berat hanya berjumlah 1 responden $(2,4 \%)$.

Hasil penelitian dianalisis normalitas menggunakan Shapiro wilk $(\mathrm{n}<50)$, diperoleh nilai signifikansi $\mathrm{p}=0.231$ dan $\mathrm{p}=0.081$ ( $p>0.05)$, maka data terdistribusi normal.
Kemudian dilanjutkan untuk mengetahui korelasinya dengan uji parametrik menggunakan uji hipotesis Pearson. Hasil uji correlation pearson menunjukkan bahwa nilai korelasinya adalah -0.425 , dengan nilai signifikansi (p) adalah 0.006. Karena nilai $\mathrm{p}<0.05$, maka disimpulkan bahwa terdapat hubungan antara persepsi lingkungan pembelajaran klinik dan tingkat kecemasan. Arah hubungan adalah negatif menunjukkan 
bahwa semakin baik persepsi lingkungan pembelajaran maka semakin rendah tingkat kecemasan, dengan interpretasi hubungan adalah sedang.

\section{PEMBAHASAN}

Terdapat hubungan yang signifikan antara persepsi lingkungan pembelajaran klinik dan tingkat kecemasan mahasiswa program profesi dokter. Arah hubungan adalah negatif menunjukkan bahwa semakin baik persepsi lingkungan pembelajaran maka semakin rendah tingkat kecemasan, dengan interpretasi hubungan adalah sedang. Lingkungan belajar dibangun melalui interaksi atara pengajar dan mahasiswa, dalam membentuk hubungan interpersonal dengan peserta didik, pengajar harus bersifat hangat dan terbuka, sangat berpusat pada peserta didik dan dapat diprediksi. ${ }^{13}$ Pengajaran dalam pembelajaran klinik berlangsung dalam suasana yang penuh rasa percaya, otentik, perhatian dimana peserta didik mendapat dukungan ketika mereka memasuki pengalaman belajar yang mungkin berisiko dan melibatkan cara baru penggunaan diri. ${ }^{14}$

Tidak ada perbedaan yang signifikan mengenai persepsi lingkungan belajar klinik antar stase. Hal ini sejalan dengan hasil penelitian Bigdeli (2015) bahwa tidak ada perbedaan yang signifikan persepsi mahasiswa tentang lingkungan belajar klinik dengan jenis kelamin. Selain itu, tidak ada perbedaan yang signifikan dari 6 item yang digunakan. Item tersebut adalah individualization, innovation, involvement, personalization, task orientation, student satisfaction. ${ }^{15}$ Fungsi kecemasan adalah memperingatkan diri sendiri akan adanya bahaya, dan merupakan isyarat bagi ego bahwa kalau tidak dilakukan tindakantindakan yang tepat maka bahaya itu akan meningkat sampai ego dikalahkan. ${ }^{16}$ Pada mahasiswa kedokteran, tingkat kecemasan yang lebih tinggi berkaitan dengan tingkat stabilitas emosional yang rendah dan kerentanan stres yang lebih tinggi. ${ }^{17}$

Interaksi antara karakteristik belajar mahasiswa dengan lingkungan belajar klinik yang akan menghasilkan cara unik dalam menghadapi lingkungan pembelajaran di rumah sakit dan menghadapi beban belajar serta kemungkinan timbulnya kecemasan. Lingkungan belajar sangatlah penting karena akan mempengaruhi pendekatan belajar yang akan diambil oleh mahasiswa dan hal ini akhirnya akan mempengaruhi pencapaian kompetensi mahasiswa. Kecemasan dianggap sebagai variabel penghalang akibat interaksi antara mahasiswa dan lingkungannya. Kecemasan bertindak sebagai penyaring yang dapat mendorong atau sebaliknya menghambat belajar mahasiswa. Keberhasilan mahasiswa dalam memenuhi beban pembelajaran akan mempengaruhi pendekatan dan keberhasilan belajar mahasiswa yang ditunjukkan dengan prestasi nyata dan persepsi terhadap pencapaiannya. ${ }^{5}$

\section{KESIMPULAN}

Terdapat hubungan yang signifikan antara persepsi lingkungan pembelajaran klinik dan tingkat kecemasan mahasiswa program profesi dokter.

\section{DAFTAR PUSTAKA}

1. Coe R, Aloisi C, Higgins S, Major LE. "What makes great teaching? Review of the underpinning research", Project Report, Sutton Trust, London, 2014 pp. $1-57 ; 2014$

2. Leman MA. Persepsi Mahasiswa Mengenai Lingkungan Belajar, Motivasi Belajar, Strategi Belajar, dan Hasil Belajar di Fakultas Kedokteran Universitas Gajah Mada Yogyakarta (Tesis). Yogyakarta : FKUGM. 2014.

3. Dunham L, Dekhtyar M, Gruener G, CichoskiKelly E, Deitz J, Elliott D, Stuber ML, et al. Medical Student Perceptions of the Learning 
Environment in Medical School Change as Students Transition to Clinical Training in Undergraduate Medical School, Teaching and Learning in Medicine. Journal Teaching and Learning in Medicine an International Journal. 2017.

4. Syahreni E, Waluyanti FT. Pengalaman Mahasiswa S1 Keperawatan Program Reguler dalam Pembelajaran Klinik. Jurnal Keperawatan Indonesia. 2007. 11(2), pp. 47-53.

5. Emilia O. Kompetensi Dokter dan Lingkungan Belajar Klinik di Rumah Sakit. Yogyakarta: Gadjah Mada University Press; 2008

6. Nadeem M, Ali A, Maqbool S, Zaidi SU. Impact of Anxiety on the Academic Achievement of Students Having Different Mental Abilities at University level in Bahawalpur ( Southern Punjab ) Pakistan. IOJES. 2012

7. Goverment Q. Mental Illness Nursing Documents. State of Queensland (Queensland Health); 2010

8. Flynn K. The Use of Standardized Patients to Minimize Anxiety in Undergraduate Nursing Students in the Clinical Setting. Master of Arts in Nursing Theses; 2012

9. Melincavage. Anxiety in student nurses in the clinical setting: a phenomenological study [dissertation]. The Pennsylvania State University; 2008

10. Al-Kadri HMF, Al-Moamary MS, Elzubair M, Magzou ME, Al Mutairi A, Roberts C, et al. Exploring factors affecting undergraduate medical students'study strategies in the clinical years : a qualitative study. Health Sci Educ 2011. 16:553-567.

11. Cook LJ. Inviting Teaching Behaviors of Clinical Faculty and Nursing Students “Anxiety”. J Nurs Educ. 2005
12. Kusumawati A, Prihatiningsih TS, Prabandari YS. Anxiety and Competence Achievement of Midwifery Students During Midwifery Clinical Practice of Maternal Neonatal Emergency. JPKI 2017. pp. 116-122

13. Nelwati, Putri TH, Rahayuningsih A. Hubungan Lingkungan Belajar Klinik dengan Tingkat Kecemasan Mahasiswa pada Program Pendidikan Ners, Ners Jurnal Keperawatan 2012. Vol 8 No 1 16-22

14. Reilly DE, Obermann MH. Pengajaran Klinis dalam Pendidikan Keperawatan. Jakarta: EGC; 2002

15. Bigdeli S, Pakpour V, Aalaa M, Shekarabi R, Sanjari M, Haghani H, et al. Clinical learning environments (actual and expected): perceptions of Iran University of Medical Sciences nursing students. MJIRI 2015. Vol 29:173

16. Hall CS, Lindzey, Gardner. Teori-Teori Psikodinamik (Klinik). Yogyakarta: Kanisius; 2009

17. Bunevicius A, Katkute A, Bunevicius R. Symptoms of Anxiety and Depression in Medical Students and in Humanities Students: Relationship With Big-Five Personality Dimensions and Vulnerability To Stress. Int J Soc Psychiatry 2008. Vol. 29:173 